\title{
Foreword to the special issue of Korean lexicography
}

\author{
Young-kuk Jeong ${ }^{1}$
}

Received: 10 August 2016/Accepted: 12 August 2016/Published online: 16 August 2016

(C) Springer-Verlag Berlin Heidelberg 2016

This special issue of Lexicography 3.1 is devoted to Korean lexicography to explore what is going on currently in the world of dictionary making and research in Korea. Studies of Korean lexicography are hard to find in international journals except for the ones by Yang (1991) and Duval (2013), which were historical surveys of Korean lexicography. The two articles dealt with Korean lexicography from pre-modern to present times as well as South and North Korean lexicography. Even though lexicographical pursuit, both in theoretical and practical aspects, has been carried out actively in Korea since the 1980s, it is not adequately introduced outside of Korea: partly due to the fact that most of the research papers are written in Korean, except only a few papers presented in English in Asialex or Euralex, and most of the topics focus on dictionary projects related to the Korean language. There are limited opportunities to introduce the research results outside of Korea. In that respect, this special issue is a valuable opportunity to look into the state of the art of Korean lexicography.

Looking back into Korean lexicographic research circles, in 1986 the Korean Lexicographic Society was founded at Yonsei University and they published the journal Sacen phyenchanhak yenkwu 'Studies in Lexicography' from the following year until 2001. Through the impact of hosting the 2nd Asialex Congress in Seoul in August, 2001, the Korean Association for Lexicography (KOREALEX) was organized in 2002, replacing the Korean Lexicographic Society, and the Journal of Korealex has been published regularly twice a year from 2003 to present, the most recent one being volume 27. Biannual conferences are also held periodically.

In the special issue section, four articles deal with current Korean lexicography from diverse points of view: an ongoing national dictionary development project, an

Young-kuk Jeong

young@igse.ac.kr

1 International Graduate School of English, Seoul, Korea 
onsite report of online dictionary development, using corpus data for lexical analysis, and devising a tool for a dictionary entry access.

Yong-un Han (Gyeoremal-keunsajeon Committee) introduces how South and North Korea have come to develop a unified Korean dictionary "On the compilation of a unified and unabridged Korean dictionary, Gyeoremal-keunsajeon". The project was first proposed in 1989 and the compilation work started in 2005. The two Koreas have been divided for over 70 years due to the differences in political systems. Because of the long period of separation and absence of communication between the countries, the languages of each Korea have developed in their own ways. As a result, an abundance of words exits which are used only in one part of the peninsula and many shared words have different meanings. It is a pressing concern for both countries to prepare a unified Korean dictionary to prepare for the future unification of the two countries. The author sketches the background of the formation of the joint committee for the project, and shows us how entry words are selected and how they are described with an example of an entry. The dictionary is expected to be published in 2019, provided that close cooperation between the two parties goes on.

Jongwan Kim (Naver Corporation) and Naeree Han (International Graduate School of English) describe the chronological development and current states of using and improving online dictionaries in South Korea in "The development of Korean online dictionaries: a case study of Naver dictionary services". This study divides the development periods into three stages from 1999 to now. They show, presenting annual user data, how rapidly the users of PC-based online dictionaries increased until 2009 and thereafter decreased by the advent of mobile-based online dictionaries. They tell us how Naver collected huge entry data by "aggregating dictionaries" and web crawling as other dictionary portals do. Recently, the Naver dictionary is increasing its entries by accepting user-contributed open dictionaries. Now Naver dictionary services are appifying answering the change of users' needs.

Kilim Nam (Kyungpook National Univ.), Hyun-ju Song (Keimyung Univ.), and Jun Choi (Kyungpook National Univ.) propose a new way of analyzing lexical bundles for the Korean dictionary in "A morpheme-based analysis of lexical bundles in Korean: an interface between corpus-driven approach and lexicography". In their study, the basic unit of analysis is different from previous studies: they are taking 'morpheme-based analysis' rather than 'word-based analysis'. So they are doing analysis of 'morphemic bundles' contrary to 'lexical bundles'. They do corpus-based quantitative analysis of morphemic bundles in various registers, then qualitative analysis in discourse functions, followed by the discussion of research findings in English and Korean corpus studies. The paper wraps up with the implication of the research for Korean lexicography.

Nikki Adams (Univ. of Maryland) reports the processes of developing a spelling corrector, especially for non-native speakers of Korean who are not acquainted with the written forms of Korean words, in "Spelling correction and morphological analysis to aid electronic dictionary look-up". The spelling corrector is combined with a morphological analyzer. The system can be used even when the users do not know the correct spelling or morphemes but do know the pronunciation of the target word. The system receives and analyzes the written form of a query word through a 
morphological analyzer and spell checker, whether it is a real or non-real word, and guides the user to the appropriate entry word of an electronic dictionary. The tool is not completed yet, but is developing in line with machines of other morphologically complex languages.

As a guest editor of the special issue, I would like to extend my heartfelt appreciation to the editor-in-chief, Prof. Yukio Tono for his active encouragement, and Dr. Susanna Bae for her enthusiastic support, as well as the reviewers for their constructive comments and suggestions.

\section{References}

Duval, M. 2013. Korean lexicography. In Dictionaries: an international encyclopedia of lexicography, ed. F.J. Hausmann, and R. Gouws, 900-910. Berlin: De Gruyter Mouton.

Yang, K.P. 1991. Korean lexicography. In Wörterbücher/Dictionaries/Dictionnaires: an international encyclopedia of lexicography, vol. 3, ed. F.J. Hausmann, et al., 2611-2617. Berlin: De Gruyter. 